\title{
THE AFFINITIES OF EOMEROPE AND DINOPANORPA (MECOPTERA)*
}

\author{
By F. M. Carpenter \\ Harvard University
}

The two fossil Mecoptera discussed below were originally described by T. D. A. Cockerell many years ago. One of them, Eomerope tortriciformis, was obtained in the Oligocene shales at Florissant, Colorado; and the other, Dinopanorpa megarche, was collected in a Miocene deposit near the Amagu River in eastern Siberia. Study of the type specimens for the present paper was made possible by the courtesy of the authorities of the Peabody Museum at Yale University, for Eomerope, and of the U. S. National Museum, for Dinopanorpa.

Eomerope was assigned by Cockerell (1909) to the mecopterous family Meropeidae, which, at that time, was a monotypic family, represented by Merope tuber Newman, a little-known species infrequently collected in the eastern part of the United States. However, a second species, Austromerope poultoni, from Western Australia, was described by Killington in 1933. These two genera, although having obvious differences in facies, are closely related, as indicated by the similar structure of the male genitalia. In his account of Eomerope, Cockerell made no reference to another mecopteron, Notiothauma reedi MacLachlan ( 1877), which occurs in part of Chile and which is the only known representative of the family Notiothaumidae. In all probability, Cockerell was not aware of this insect, since its existence was not generally made known until the publication of Esben-Petersen's monograph of the Mecoptera in I92I. From my study of the type of Eomerope and comparisons with specimens of Merope and Notiothauma, I am convinced that Eomerope belongs to the family Notiothaumidae instead of the Meropeidae. The reasons for this conclusion are given below, following the account of the genus and species.

\section{Family Notiothaumidae Esben-Petersen}

\section{Genus Eromerope Cockerell}

Eomerope Cockerell, 1909, p. 381

Wing venation as in Notiothauma but with fewer cross veins, the

*Partial financial support of this research is acknowledged to the National Science Foundation (Grant no. GB 27333, F. M. Carpenter, Harvard University, principal investigator). 

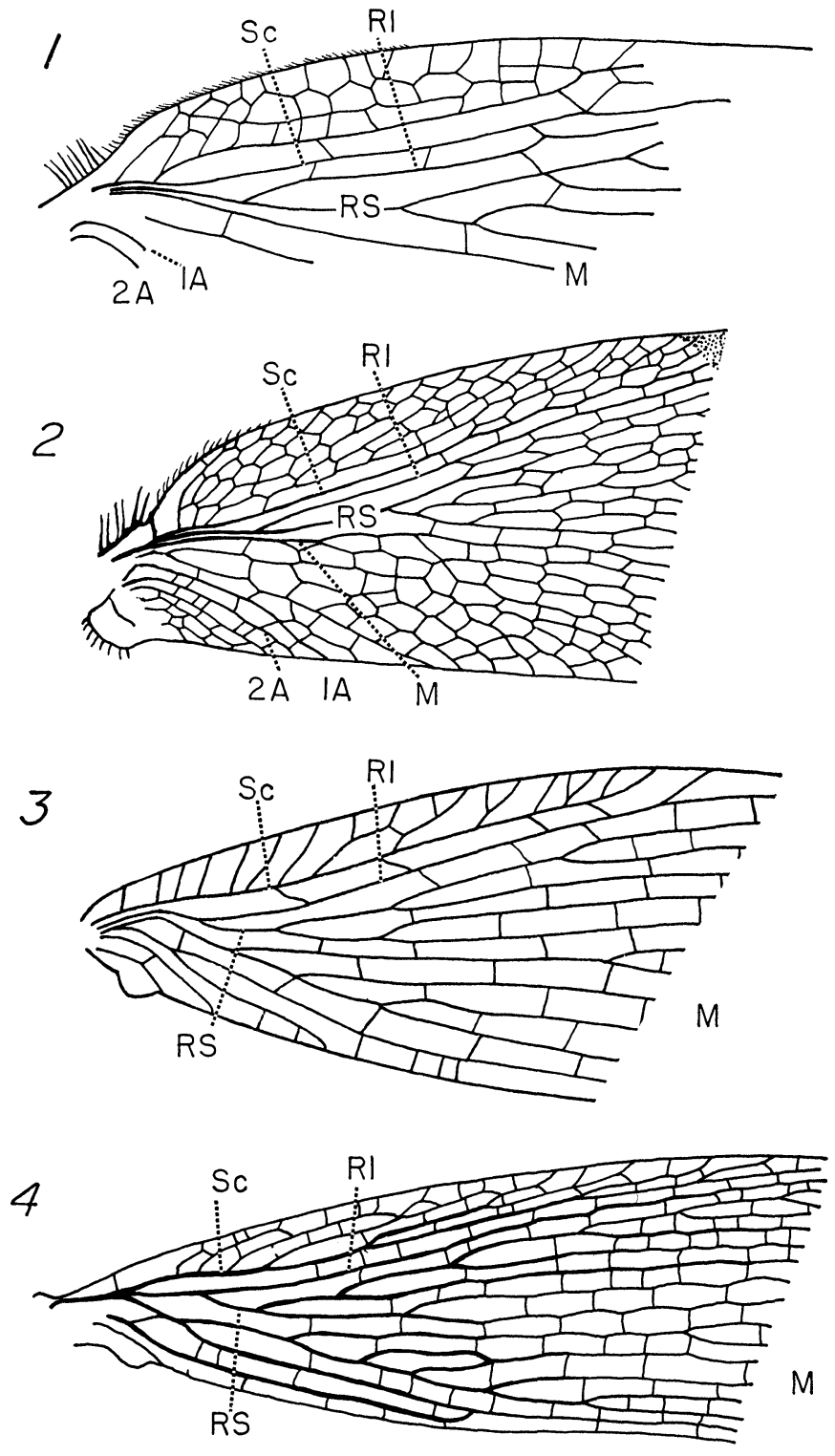
number of cellules being about half that in Notiothauma.

Type species: Eomerope tortriciformis Cockerell.

\section{Eomerope tortriciformis Cockerell}

Figs. I and 5

Eomerope tortriciformis Cockerell, 1909, p. 381

Length of fore wing, I $4 \mathrm{~mm}$.; length of body, $13 \mathrm{~mm}$. The wing expanse of the insect was about $32 \mathrm{~mm}$., some IO $\mathrm{mm}$. less than N. reedi.

Type: No. 26i76, Peabody Museum, Yale University; collected at Florissant, Colorado, in 1907.

The specimen shows the whole insect (see figure 5). The wings are almost symmetrically arranged, with a pair on each side slightly overlapped; the veins in the apical and posterior regions of both pairs are not discernible. The legs are long and unusually spinose, as in Notiothauma. The specimen, obviously a male, has the Ioth abdominal segment forming a characteristic genital bulb, comparable to that in Notiothauma (see Crampton, 1931).

The preserved part of the venation of the fore wing is shown in figure I. At the base of the wing is a cluster of heavy setae, as in Notiothauma. The costal area is abruptly narrowed basally. Sc is a distinct vein, as in Notiothauma, with a series of irregular veinlets arising anteriorly from its basal branch. $\mathrm{R}_{\mathrm{I}}$ arises from $\mathrm{Rs}$, as in Notiothauma, by diverging anteriorly, Rs continuing the straight line of $R$; only a few of the basal branches of Rs are preserved; IA and $2 \mathrm{~A}$ are represented only by their curved basal portions that strongly resemble the curved bases of Notiothauma. The venation of the anterior-basal part of the hind wing is like that of the fore wing.

The similiarity of the venation of Eomerope to that of Notiothauma is at once obvious by comparing figure I with figure 2, which shows the basal part of the wing of Notiothauma. The venational pattern is essentially the same, the only notable difference being the smaller number of cross veins and cellules in Eomerope. The differ-

Figure 1. Eomerope tortriciformis Cockerell; drawing of preserved part of fore wing, based on holotype (original).

Figure 2. Notiothauma reedi MacLachlan; drawing of proximal part of fore wing (after Crampton, 1930).

Figure 3. Merope tuber Newman; drawing of proximal part of fore wing (original).

Figure 4. Austromerope poultoni Killington; drawing of proximal part of fore wing (after Killington, 1933). 


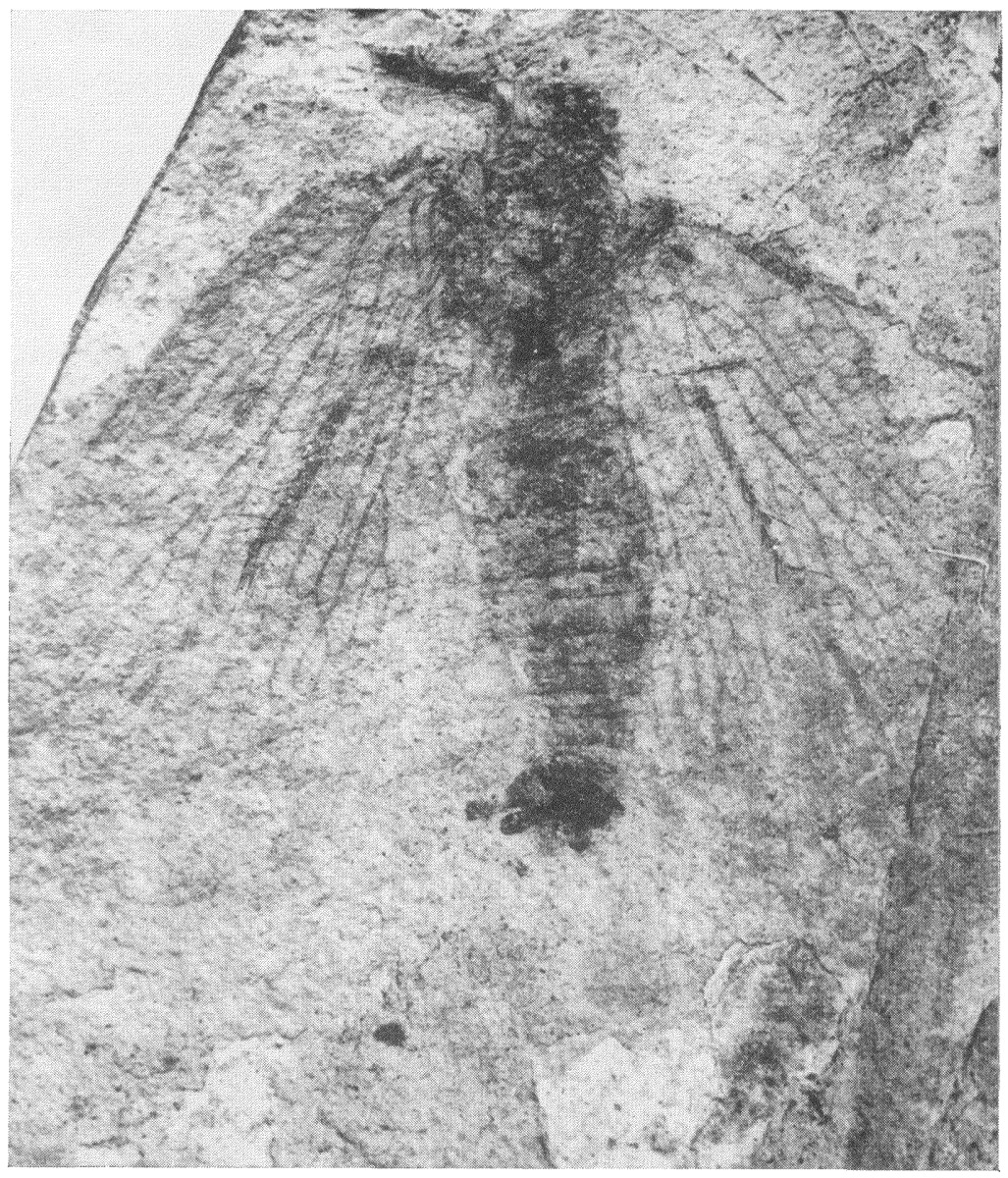

Figure 5. Eomerope tortriciformis Cockerell; photograph of holotype; length of fore wing, $14 \mathrm{~mm}$. 
ences between Eomerope and the two genera of Meropeidae are readily apparent by considering figures 3 (Merope) and 4 (Austromerope). In Merope the costal area is relatively narrow and lacks cellules; Rs diverges posteriorly from $\mathrm{R}_{\mathrm{I}}$. In Austromerope the costal area is also narrow, though there are a few cellules; $R_{I}$, not $\mathrm{Rs}$, continues the straight line of $\mathrm{R}$, Rs diverging posteriorly from $\mathrm{R}_{\mathrm{I}}$; and the anal veins do not have distinctly curved bases.

From the evidence of the wing venation, it is clear that Eomerope is more closely related to Notiothauma than to the Meropeidae, but stronger evidence is furnished by the structure of the abdomen in the male. In the Meropeidae the males lack the genital bulb characteristic of most Mecoptera but possess a pair of long claspers, which extend far beyond the end of the abdomen, especially in Austromerope. In Eomerope, the abdomen has the small bulb like that of Notiothauma, with very short forceps that do not extend beyond the abdomen.

\section{Family Dinopanorpidae, new family}

Large Mecoptera, related to the Orthophlebiidae and Panorpidae. Hind wing: several strong cross veins between Sc and costal margin; $\mathrm{R}_{\mathrm{I}}$ extending almost to wing apex, curving posteriorly near its termination; Rs with at least 8 terminal branches, all directed posteriorly near the wing margin; $M$ with at least 5 branches; stem of $\mathrm{Cu}$ free at base; $\mathrm{CuA}$ coalesced with $\mathrm{M}$ for a short distance basally and $\mathrm{CuP}$ coalesced with IA; first basal cross vein $(m-c u)$ between $\mathrm{CuA}$ and MP very long and oblique; cross veins more numerous than in Panorpidae and Orthophlebiidae. Fore wing and body unknown.

\section{Genus Dinopanorpa Cockerell}

Dinopanorpa Cockerell, 1924, p. 2

Hind wing: costal space relatively broad (for a hind wing), with 5 strong veinlets to margin; stem of $\mathrm{Cu}$ somewhat closer to IA than to $M$.

Type species: Dinopanorpa megarche Cockerell.

\section{Dinopanorpa megarche Cockerell}

Figs. 6 and 9

Dinopanorpa megarche Cockerell, 1924, p. 2

Length of hind wing, $30 \mathrm{~mm}$; maximum width, Io $\mathrm{mm}$.; estimated wing expanse, $65 \mathrm{~mm}$. Other specific characteristics are diffcult to designate, in the absence of the fore wing and body; however, the number and arrangement of cross veins would almost certainly 

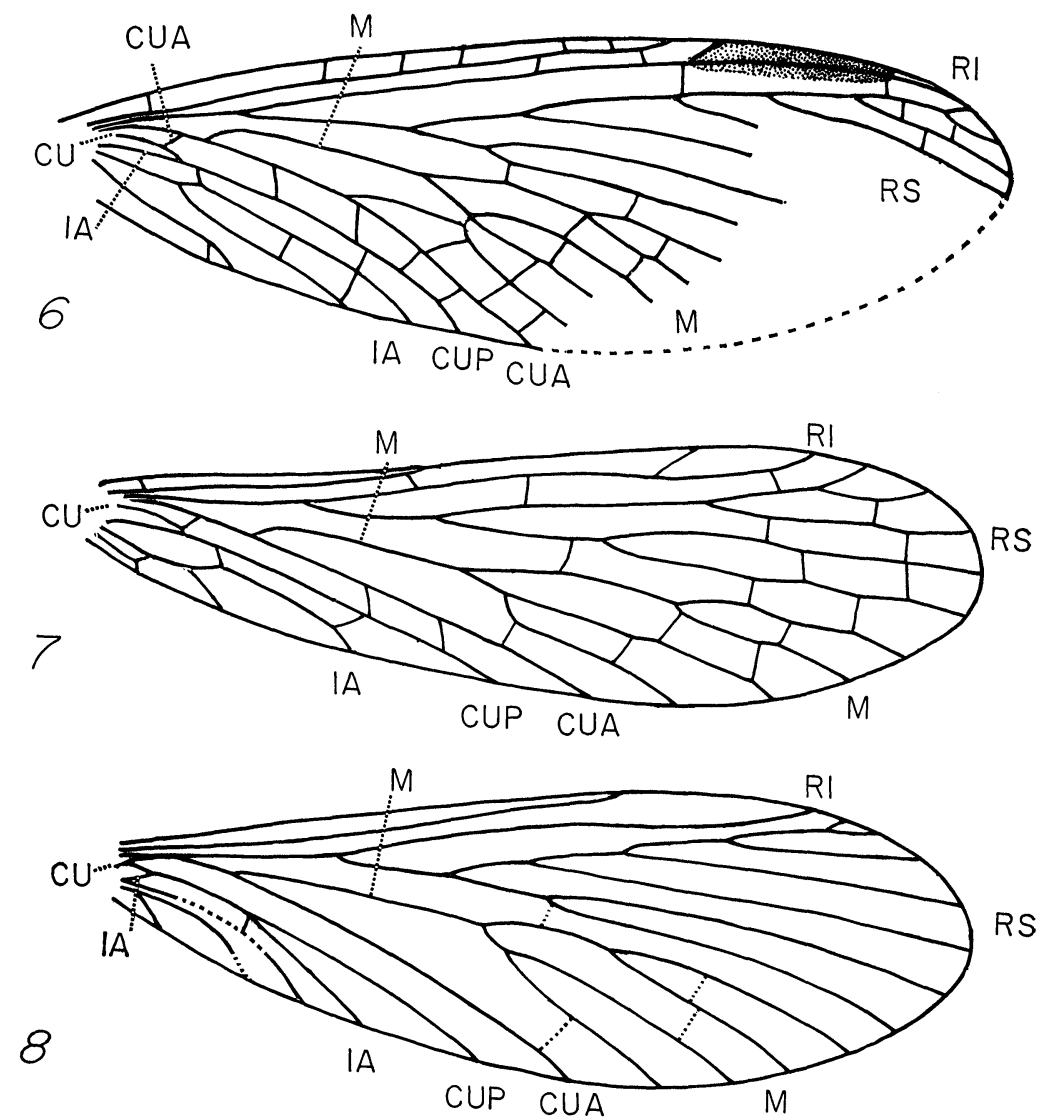

Figure 6. Dinopanorpa megarche Cockerell; drawing of hind wing, based on holotype (original).

Figure 7. Panorpa nebulosa Westwood; drawing of hind wing (original).

Figure 8. Orthophlebia liassica Mantell; drawing of hind wing (after Tillyard, 1933). 


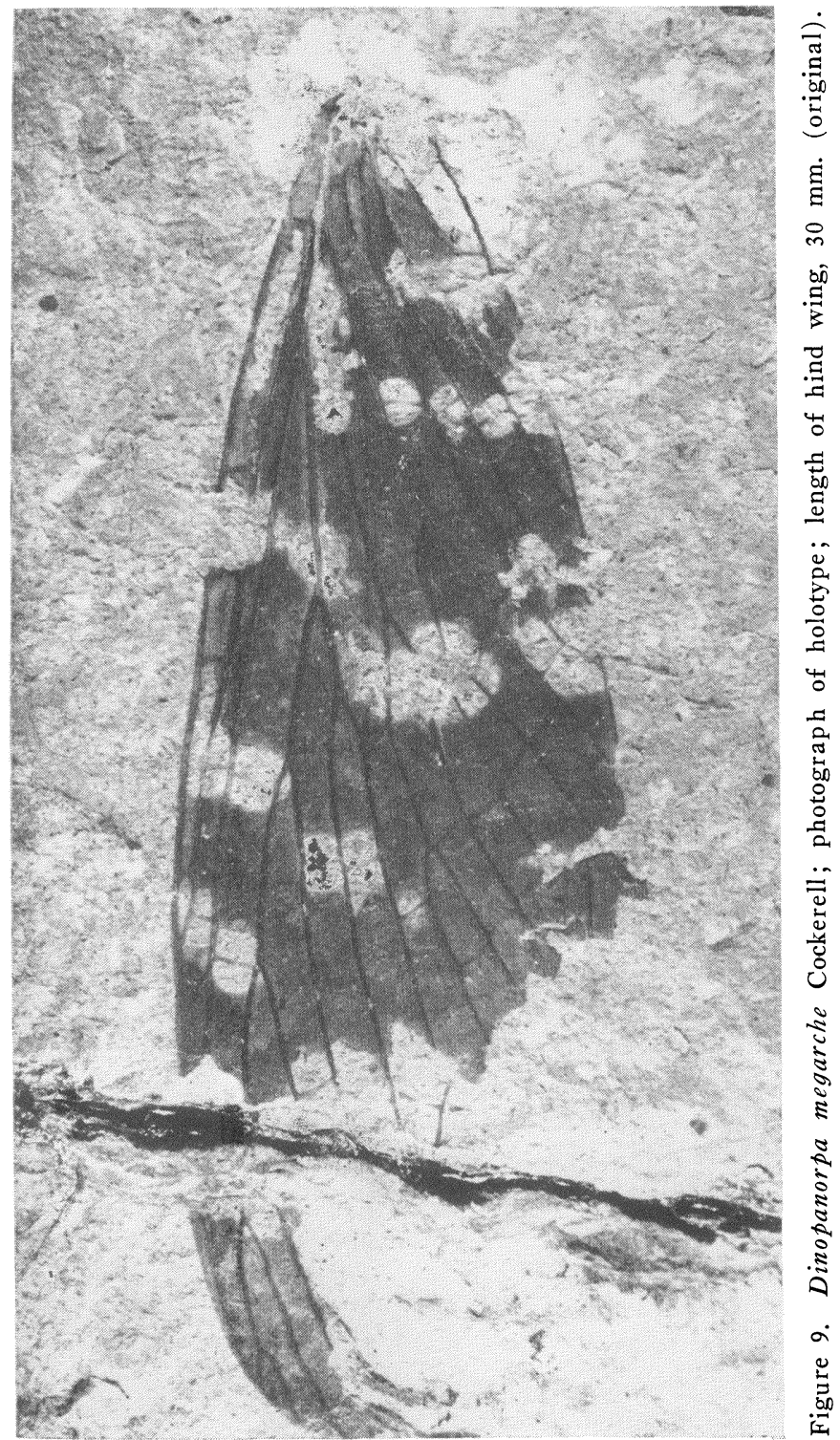


be in this category. Details of the venation are shown in figure 6 . As preserved, the wing is dark brown, with several white spots and bands (figure 9), as frequently seen in existing panorpids.

Type: No. 69173, U. S. National Museum; collected by A. Kuznetzov, "on the Amagu River, Maritime Province, coast of Siberia, opposite the southern end of Sakhalin Island." Rohdendorf (1957) records the locality as in the Lower Amursk Region of the USSR, on the bank of the Kudya River, a tributary of the Amagu River, and indicates its age as Lower Miocene. Cockerell states (1924) that the flora of the deposit, including such genera as Ginko, Cornus, Taxodium, and Quercus, indicates a warm-temperate climate.

The type specimen consists of a very well-preserved hind wing, lacking only a part of the apical-posterior region (figure 9).

Cockerell placed Dinopanorpa in the family Panorpidae, Tillyard (1933, p. 26) transferred it to the extinct family Orthophlebiidae (otherwise known only from the Triassic and Jurassic periods) and Martynova (1962, p. 29I) considered it a synonym of Orthophlebia in the same family. Actually, as noted by Cockerell, Dinopanorpa presents, in the hind wing, a remarkable combination of characters. The presence of 5 strong veinlets between Sc and the costal margin is a feature that does not occur in the Orthophlebiidae or Panorpidae, although it is seen in some of the Permian and Triassic genera of other families. The form of $\mathrm{R}_{\mathrm{I}}$, extending nearly to the wing apex and directed posteriorly in the apical region, is unique in the known Mecoptera, extinct and Recent, as noted by Cockerell; in other members of the order, $\mathrm{RI}_{\mathrm{I}}$ is much shorter and is curved anteriorly at its termination. Cross veins are at least twice as numerous in Dinopanorpa as in the Panorpidae and Orthophlebiidae. Another peculiar feature, also noted by Cockerell, is the long and oblique $\mathrm{m}$-cu cross vein (figure 6), although it could be an abnormality in this particular wing. In contrast, the structure of $\mathrm{Cu}$, including its stem, the nature of its branching and the coalescence of $\mathrm{CuA}$ and $\mathrm{CuP}$ (with $\mathrm{M}$ and $\mathrm{I} A$ respectively), is virtually identical with that in the Panorpidae (figure 7) but, incidentally, quite unlike that of Orthophlebia (figu:e 8). The extensive branching of Rs, with at least 8 terminal branches, is totally unlike the condition in the Panorpidae, with 5 branches to Rs. Dinopanorpa also has a 5branched $M$, although that vein is rarely more than 4 -branched in Panorpidae.

In view of the differences and peculiarities noted above, assignment of Dinopanorpa to either Orthophlebiidae or Panorpidae seems un- 
justified. The position of the Dinopanorpidae in the mecopteran phylogeny will remain obscure until the fore wing and body structures are known. However, it can hardly be considered intermediate between the Panorpidae and Orthophlebiidae because of the peculiar form of RI and Rs and the presence of costal veinlets. More likely, it is a specialized derivative of some early Mesozoic stock, close to the Orthophlebiidae.

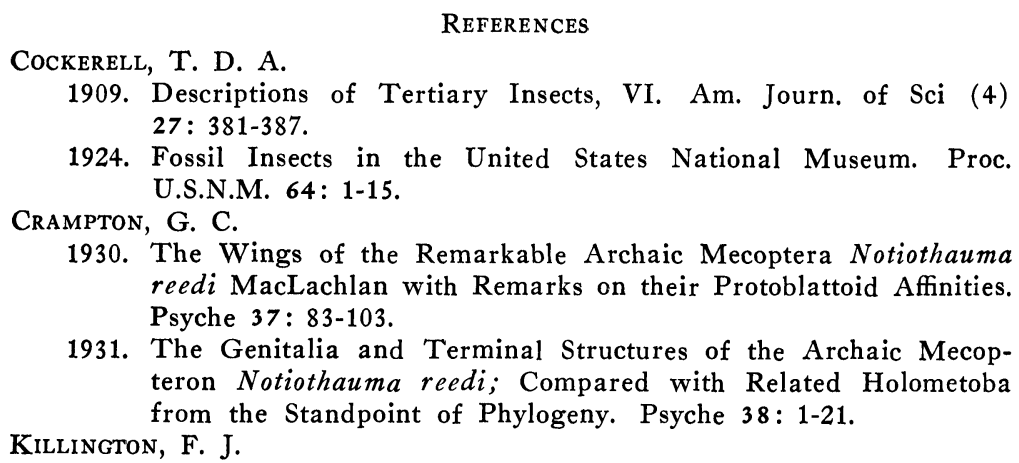

1909. Descriptions of Tertiary Insects, VI. Am. Journ. of Sci (4) 27: 381-387.

1924. Fossil Insects in the United States National Museum. Proc. U.S.N.M. $64: 1-15$.

Crampton, G. C.

1930. The Wings of the Remarkable Archaic Mecoptera Notiothauma reedi MacLachlan with Remarks on their Protoblattoid Affinities. Psyche 37: 83-103.

1931. The Genitalia and Terminal Structures of the Archaic Mecopteron Notiothauma reedi; Compared with Related Holometoba from the Standpoint of Phylogeny. Psyche 38: 1-21.

KILLINGTON, F. J.

1933. A New Genus and Species of Meropeidae (Mecoptera) from Australia. Ent. Mo. Mag. 69: 1-4.

Martynova, O.

1962. Mecoptera, in Osnovy (Insecta), pp. 283-294.

ROHDENDORF, B. B.

1957. Paleoentomological Investigation in the USSR. Trudy Paleont. Inst. 66: $1-100$.

Tillyard, R. J.

1933. The Panorpoid Complex in the British Rhaeic and Lias. Brit. Mus. Fossil Insects, No. 3: 1-79. 

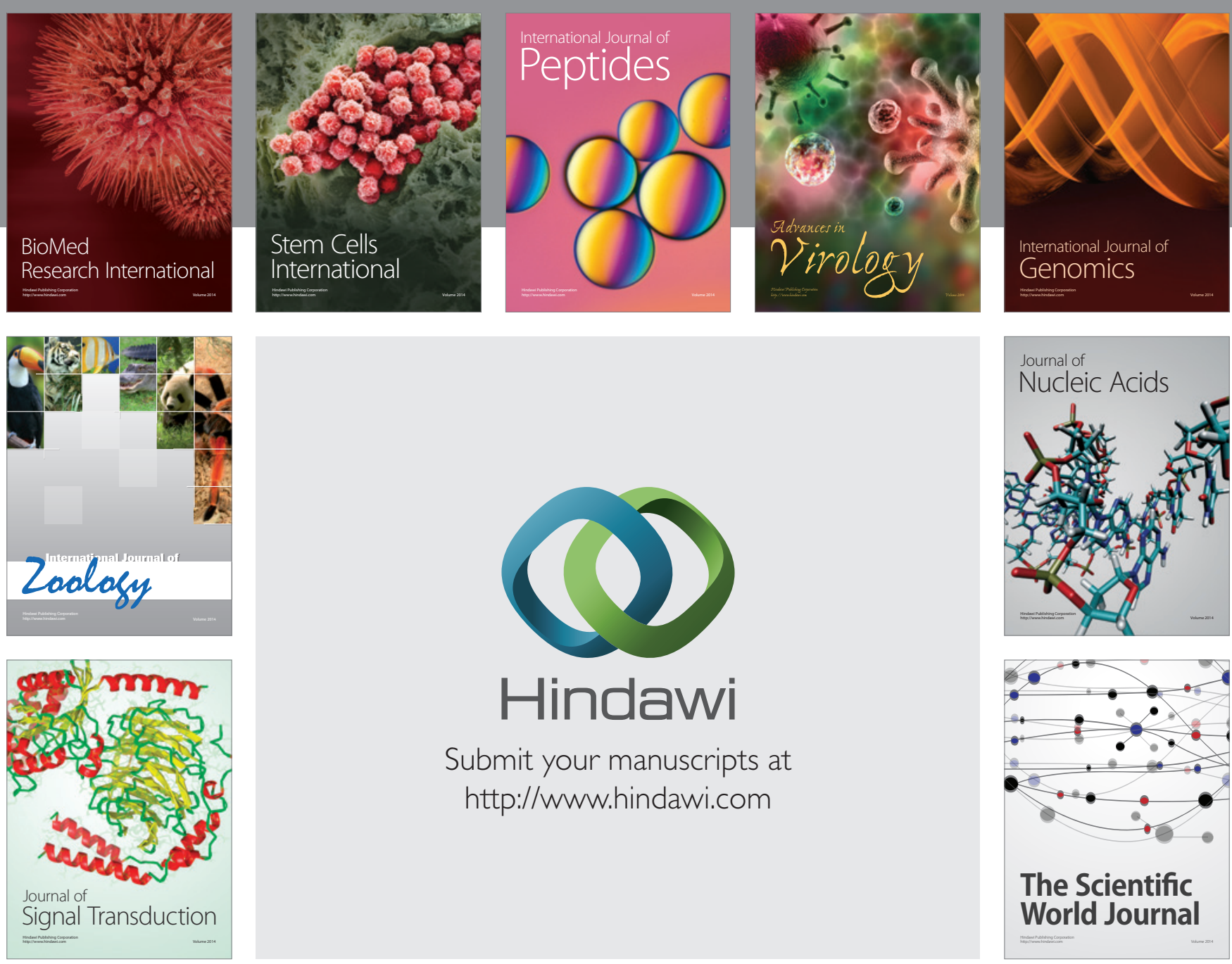

Submit your manuscripts at

http://www.hindawi.com
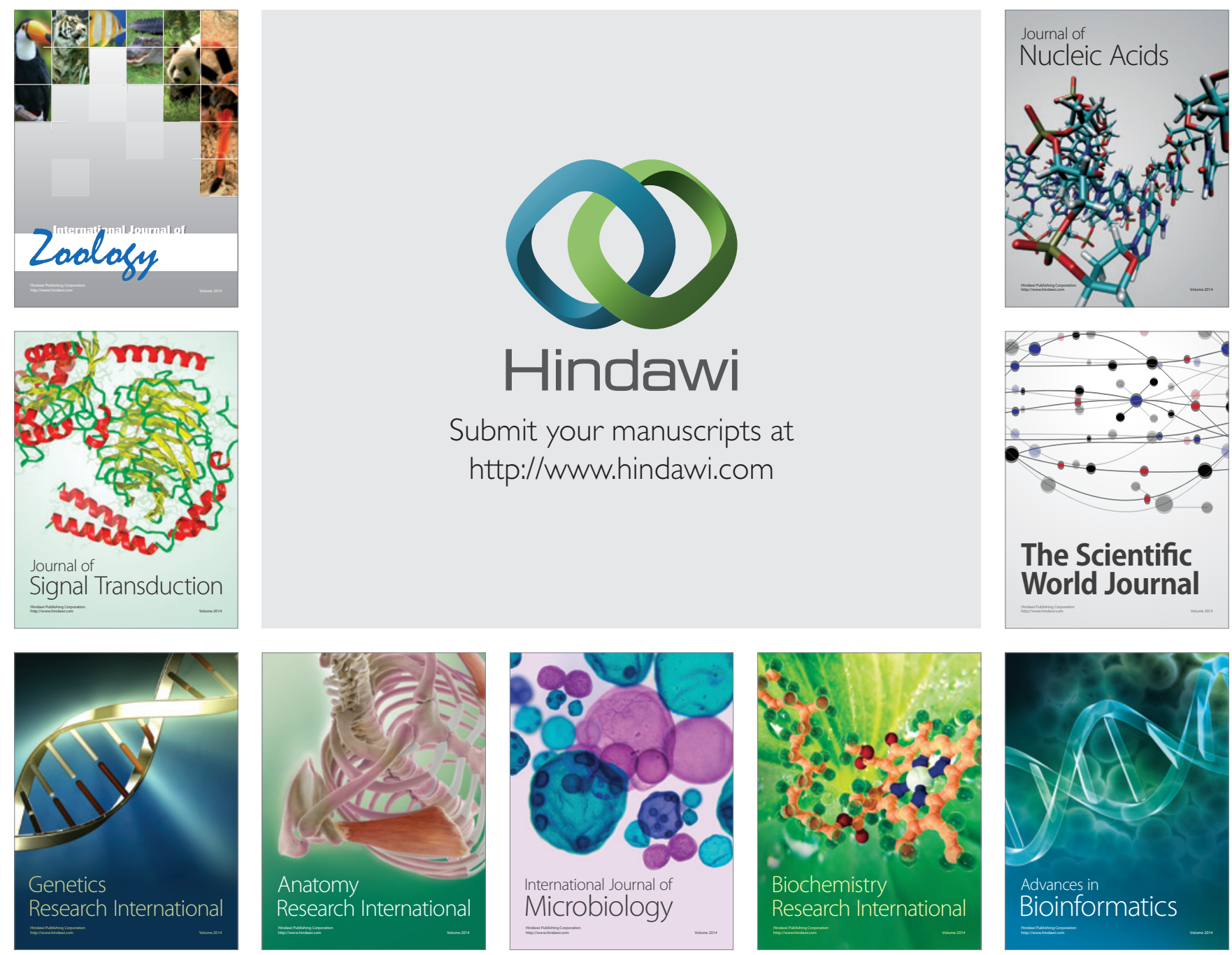

The Scientific World Journal
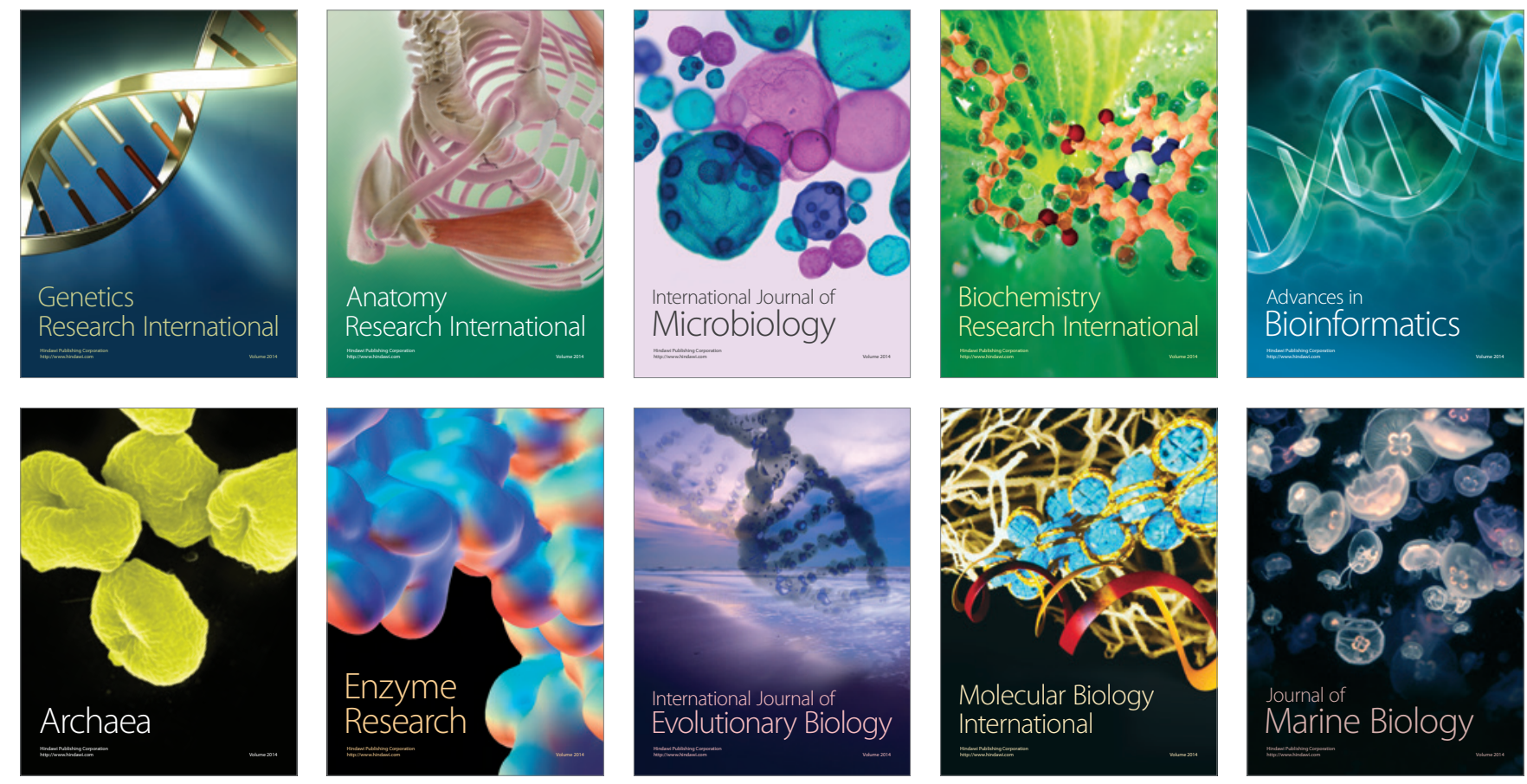